\title{
浑善达克沙地榆树疏林自然保护区核心区 设计的初步研究
}

\section{彭 羽1,2 蒋高明 $1^{*} \quad$ 李永庚 ${ }^{1} \quad$ 刘美珍 $^{1} \quad$ 牛书丽 $^{1} \quad$ 于顺利 ${ }^{1} \quad$ 杨道斌 3}

（1 中国科学院植物研究所植被数量生态学重点实验室, 北京 100093）（2 中国科学院研究生院, 北京 100039)

(3 北京大学人口研究所, 北京 100871)

摘 要 为了保护浑善达克沙地榆树 (Ulmus pumila) 疏林景观, 拟建立自然保护区。基于榆树疏林植被图,运用 ArcGIS分析榆树疏林斑块数量、面积、破碎化程度,发现该区榆树疏林斑块大小差异较大,小斑块较多,斑块边界割 裂严重, 破碎化程度高, 需要及时加以保护。按照景观生态学原理、生物岛屿地理学设计自然保护区原则, 选择疏 林斑块集中分布区, 作为潜在核心区,运用 ArcGIS 的缓冲区分析功能,设计不同的宽度,发现斑块边界向外延伸 3 $\mathrm{km}$ 能够连接较多的斑块, 而占用较少的非疏林斑块土地面积。同时调查斑块外不同距离样方与疏林斑块的群落 相似度, 发现 $1 \mathrm{~km}$ 以内能够包含大于 $10 \%$ 相似度的群落。由此而初步确定的核心区分布在正蓝旗 23 个嘎查, 面积 $1531 \mathrm{~km}^{2}$, 约占全旗总面积的 $13 \%$ 。

关键词 自然保护区 核心区 规划设计 浑善达克沙地疏林 景观破碎化

\section{DETERMINATION OF THE PRIMARY CORE ZONE OF THE PLANNED HUNSHANDAK NATURE RESERVE}

\author{
PENG Yu ${ }^{1,2} \quad$ JIANG Gao-Ming $^{1}$ LI Yong-Geng ${ }^{1} \quad$ LIU Mei-Zhen ${ }^{1}$ \\ NIU Shu-Li ${ }^{1}$ YU Shun- $\mathrm{Li}^{1}$ and YANG Dao-Bin ${ }^{3}$ \\ (1 Laboratory of Quantitative Vegetation Ecology, Institute of Botany, Chinese Academy of Sciences, Beijng 100093, China) \\ (2 Graduate School of Chinese Academy of Sciences, Beijing 100039, China) \\ (3 Institute of Population, Peking University, Beijing 100871, China)
}

\begin{abstract}
There are many patches of Ulmus pumila forests distributed in the Hunshandak Sandland, most of them located in the Zhenglan Banner, Inner Mongolia, China. These forest patches are important for combating desertification and sandstorm, conserving biological diversity and landscape views. In order to protect Ulmus pumila forests, the establishment of a nature reserve has been planned for the Hunshandak Sandland. The core zone of the planned nature reserve was determined based on principles of island biogeography theory and landscape ecology theory. First, a map of the distribution region of Ulmus pumila forest patches, a map of communication, and a map of the administrative system of Zhenglan Banner were transferred into a computer. Using ArcGIS software, the patch size, patch distribution, patch density, patch distance, patch segmentation and fragmentation were analyzed. We found that the sparse forest patches were mainly distributed in 20 village regions, and each patch was an average of $0.96 \mathrm{~km}^{2}$. For these 20 villages, the patch density ranged from 0.10 to $0.24 \mathrm{~km}^{-2}$, the edge density ranged from 2.50 to $12.50 \mathrm{~km}^{-1}$, and separating degree ranged from 0.4 to $1.20 \mathrm{~km}$. These indices showed that fragmentation is a serious problem and these forests need to be protected. In order to select the proper sites to make up the core zone, ArcGIS buffer analysis was used to determine the minimum distance necessary to unite the patches into one zone. Most patches could be united using a distance of $3 \mathrm{~km}$. By examining changes in the plant community, a $1 \mathrm{~km}$ buffer region around each patch had the greatest value for protection. Thus, a $10 \mathrm{~km}$ buffer around the patches could guarantee that most objects would be protected and occupy the least amount of area. According to guidelines for nature reserve planning based on principles of island biogeography, the rest of the zones within the buffer lines need to be included into the core zone. Therefore, the planned core zone will be $1531 \mathrm{~km}^{2}$ and occupy $13 \%$ of total Zhenglan Banner nature reserve. We also discuss how to determine the shape of the core zone with respect to edge effects.
\end{abstract}

Key words Nature reserve, Core zone, Design, Hunshandak sandland, Landscape fragmentation 
自然保护区的规划设计涉及保护区的位置、面 积、数量以及内部功能区划。其中重要部分当属于 核心区的确定与设计 (马克平, 2001)。目前, 自然保 护区设计的主要理论包括岛屿生物地理学原理 (MacArthur-Wilson 学说)、最小可存活种群( MVP) 理 论、异质种群 (Meta-population) 学说、景观镶嵌理论 等 (Kingsland, 2002; 李义明和李典谟, 1996; 邬建 国，1990）。唐小平(2003)介绍了中国三江源自然保 护区设计的生物区域规划与管理方法, 李文华等 (2000)介绍了新疆艾比湖自然保护区的规划, 崔国 发等(2000)利用重点植物群落分布格局规划了北京 市喇叭沟门自然保护区, 基本上基于以上保护区设 计理论。

浑善达克沙地榆树 ( Ulmus pumila) 疏林景观, 具 有重要的保护价值。保护好浑善达克沙地榆树疏 林, 能够防止沙尘暴、涵养水源、防止水土流失、防治 荒漠化和牧民贫困。在内蒙古正蓝旗人民政府以及 联合国教科文组织干旱区有限资源可持续管理项目 支持下, 人与生物圈计划中国国家委员会组织生态、 植物、动物、经济、地理、地质、社会文化等方面的专 家对浑善达克沙地拟建自然保护区地区进行了为期 3 年的连续考察。根据考察结果, 本文运用景观生 态学原理, 结合自然保护区设计原则和 ArcGIS工 具,对拟建自然保护区核心区进行了初步设计。

\section{1 研究地区概况与研究方法}

\section{1 研究地区概况}

拟建自然保护区位于浑善达克沙地腹地正蓝旗 ( $\left.41^{\circ} 46^{\prime} \sim 43^{\circ} 69^{\prime} \mathrm{N} ; 114^{\circ} 55^{\prime} \sim 116^{\circ} 38^{\prime} \mathrm{E}\right)$, 该区属中 温带半干早大陆性季风气候, 天然分布着以沙地榆 为建群种的沙地草原疏林, 包含固定沙丘、流动沙 丘、半流动沙丘、丘间低地、湿地等生境类型。正蓝 旗区域辖 3 个镇、 8 个苏木(乡)和 3 个国营农牧场, 2001 年可利用草场占 $81.8 \%$, 其中退化沙化草场占 $88 \%$, 总人口 7.84 万人, 非农业户口 2.49 万人, 牧 民人均纯收入 1600 元, 该旗 2000 年财政收入 2042 万元, 2002 年为 1751 万元。

\section{2 研究方法}

经专家咨询和野外实地考察, 以内蒙古林业勘 察设计院编制的 $1: 22$ 万正蓝旗榆树疏林林斑分布 图为底图, 将林斑分布图数字化输入计算机, 采用 ArcGIS 软件, 统计每个疏林斑块的面积和周长, 为了 便于比较分析, 以每个嘎查 (行政村) 为单位计算斑 块总面积和周长、斑块数、破碎化程度。同时, 输入
同比例尺的该区土地利用类型图、交通旅游图、政区 图等图件, 形成叠加主题, 以便对核心区的边界作出 决策。在景观尺度和景观斑块尺度上, 还采用以下 指标:

\subsection{1 斑块密度}

斑块密度为研究区内斑块个数与研究区面积的 比值 (Huslshoff, 1995):

$$
P D=\sum n_{i} / A
$$

式中: $P D$ 表示斑块密度; $\sum n_{i}$ 表示研究区 (全旗或 者嘎查)斑块总数; $A$ 表示研究区(全旗或者嘎查)面 积。 $P D$ 值越大, 表明破碎化程度愈高。

\subsection{2 斑块分离度}

分离度是指某一景观中不同斑块个体空间分布 的离散(或集聚)程度 (Riitters et al., 1995)。公式为

$N_{i}=D_{i} / S_{i}$

式中: $N_{i}$ 为研究区 $i$ 内疏林斑块的分离度指数; $D_{i}$ 为研究区 $i$ 内斑块的距离指数, $D_{i}=\frac{1}{2} \sqrt{\frac{n}{A}}, n$ 为研 究区 $i$ 的斑块数; $S_{i}$ 为研究区 $i$ 的面积指数, $S_{i}=$ $A_{i} / A, A_{i}$ 为研究区 $i$ 内的斑块面积。

\subsection{3 边界密度}

景观边界密度是指研究区域内景观斑块周长与 面积的比值 (Schumaker, 1996)。

\subsection{4 群落相似度}

群落相似度表示取样群落与标准群落之间的相 似程度。2003 年 8 月, 在典型的榆树疏林斑块边界 (位于正蓝旗贺日斯台苏木巴音胡舒嘎查) 选取 5 个 草本样方, 作为参照标准, 以此为圆点, 沿疏林斑块 边界垂直方向向前分别在 100、300、500、800 和 1000 $\mathrm{m}$ 的地点选取 5 个样方, 样方大小均为 $2 \mathrm{~m} \times 2 \mathrm{~m}$ 。 调查各个样方的植物物种数目, 记录与标准样方相 同的植物物种数目。共计选取 5 个圆点, 调查了 130 个草本样方。按照以下公式( Pielou, 1994)计算取样 点与标准群落之间的群落相似度:

$$
P_{\mathrm{SNV}}=\frac{2 \times \sum_{\text {min }}\left(A_{i v}, A_{\text {ivref }}\right)}{\sum A_{i v}+\sum A_{\text {ivref }}} \times 100
$$

式中: $P_{\mathrm{SNV}}=$ 群落相似度; $A_{i v}=$ 样方群落物种数; $A_{\text {ivref }}=$ 核心区群落物种数; 公式分子为取样群落和 标准群落之间相同的物种数目, 再乘以 2 。各个取 样点的群落相似度取平均值进行分析应用。

\section{2 结果与分析}

\section{1 疏林斑块总体特征}

本研究区域总面积 $10182 \mathrm{~km}^{2}$, 共含有榆树疏 
林斑块 802 个, 斑块面积共计 $835 \mathrm{~km}^{2}$, 占全旗总面 积的 $8.2 \%$, 平均斑块面积为 $0.96 \mathrm{~km}^{2}$, 表明破碎化 程度严重。最大斑块面积为 $18 \mathrm{~km}^{2}$, 出现在贺日斯 台苏木舒日根台林场。其它面积较大的斑块面积为 12、10、10、9、7 和 $7 \mathrm{~km}^{2}$, 分别位于桑根达来镇柴达和 嘎查、乌日图苏木蒙古勒金嘎查、贺日斯台苏木查干 敖包嘎查、舒日根台林场、赛音胡都嘎苏木那日斯图 嘎查和贺日斯台苏木图古日格嘎查, 面积大于 $5 \mathrm{~km}^{2}$ 的大斑块较多, 占斑块总面积的 $12 \%$, 小于 $2 \mathrm{~km}^{2}$ 的
小斑块数量也较多, 占斑块总数量的 $43 \%$ 。

按照嘎查、村、村级林场为单位分析斑块特征, 发现榆树疏林斑块主要分布于 20 个嘎查, 其它嘎查 所含斑块面积较小, 都在 $2 \mathrm{~km}^{2}$ 以下, 很多嘎查则没 有斑块分布。因此, 我们确定 20 个嘎查作为潜在核 心区加以分析。这 20 个嘎查所含斑块的面积、个 数、斑块密度、平均面积、边界密度、距离指数、面积 指数、分离度列于表 1 。

表 1 主要分布区榆树疏林斑块特征

Table 1 The traits of Ulmus pumila sparse forest patches in the main distributed areas in Hunshandak Sandland, China

\begin{tabular}{|c|c|c|c|c|c|c|c|c|c|}
\hline $\begin{array}{l}\text { 代码 } \\
\text { Code }\end{array}$ & $\begin{array}{c}A \\
\left(\mathrm{~km}^{2}\right) \\
\end{array}$ & $P N$ & $\begin{array}{c}P D \\
\left(\mathrm{~km}^{-2}\right) \\
\end{array}$ & $\begin{array}{c}D_{i} \\
(\mathrm{~km})\end{array}$ & $\begin{array}{c}A_{i} \\
\left(\mathrm{~km}^{2}\right)\end{array}$ & $\begin{array}{c}A A_{i} \\
\left(\mathrm{~km}^{2}\right) \\
\end{array}$ & $\begin{array}{c}E D \\
\left(\mathrm{~km}^{-1}\right) \\
\end{array}$ & $S_{i}$ & $\begin{array}{c}N_{i} \\
(\mathrm{~km}) \\
\end{array}$ \\
\hline $\mathrm{T}_{1}$ & 49 & 12 & 0.25 & 0.22 & 14 & 1.16 & 9.65 & 0.29 & 0.76 \\
\hline $\mathrm{T}_{2}$ & 79 & 17 & 0.20 & 0.22 & 42 & 2.47 & 4.72 & 0.53 & 0.41 \\
\hline $\mathrm{T}_{3}$ & 65 & 7 & 0.11 & 0.16 & 11 & 1.57 & 8.93 & 0.17 & 0.93 \\
\hline $\mathrm{T}_{4}$ & 31 & 6 & 0.19 & 0.20 & 11 & 1.83 & 5.57 & 0.35 & 0.58 \\
\hline $\mathrm{T}_{5}$ & 72 & 11 & 0.14 & 0.18 & 26 & 2.36 & 4.81 & 0.36 & 0.48 \\
\hline $\mathrm{T}_{6}$ & 49 & 14 & 0.28 & 0.24 & 29 & 2.07 & 2.93 & 0.59 & 0.43 \\
\hline $\mathrm{T}_{7}$ & 43 & 8 & 0.19 & 0.21 & 10 & 1.25 & 6.96 & 0.23 & 0.91 \\
\hline $\mathrm{T}_{8}$ & 38 & 6 & 0.14 & 0.19 & 8 & 1.33 & 10.90 & 0.21 & 0.88 \\
\hline $\mathrm{T}_{9}$ & 76 & 22 & 0.28 & 0.35 & 30 & 1.36 & 3.55 & 0.39 & 0.88 \\
\hline $\mathrm{T}_{10}$ & 76 & 19 & 0.24 & 0.24 & 19 & 1.00 & 8.98 & 0.25 & 0.92 \\
\hline $\mathrm{T}_{11}$ & 46 & 13 & 0.29 & 0.23 & 14 & 1.08 & 4.51 & 0.30 & 0.80 \\
\hline $\mathrm{T}_{12}$ & 110 & 23 & 0.19 & 0.23 & 38 & 1.65 & 4.03 & 0.35 & 0.60 \\
\hline $\mathrm{T}_{13}$ & 101 & 18 & 0.24 & 0.21 & 23 & 1.28 & 5.28 & 0.21 & 0.92 \\
\hline $\mathrm{T}_{14}$ & 132 & 17 & 0.09 & 0.17 & 20 & 1.18 & 10.80 & 0.15 & 1.01 \\
\hline $\mathrm{T}_{15}$ & 104 & 12 & 0.24 & 0.17 & 20 & 1.67 & 5.14 & 0.19 & 0.82 \\
\hline $\mathrm{T}_{16}$ & 77 & 21 & 0.23 & 0.24 & 22 & 1.05 & 8.74 & 0.29 & 0.82 \\
\hline $\mathrm{T}_{17}$ & 142 & 24 & 0.14 & 0.20 & 28 & 1.17 & 3.74 & 0.20 & 0.96 \\
\hline $\mathrm{T}_{18}$ & 155 & 26 & 0.14 & 0.20 & 31 & 1.19 & 2.54 & 0.20 & 0.96 \\
\hline $\mathrm{T}_{19}$ & 261 & 37 & 0.14 & 0.18 & 39 & 1.05 & 2.50 & 0.15 & 1.16 \\
\hline $\mathrm{T}_{20}$ & 91 & 19 & 0.18 & 0.23 & 22 & 1.16 & 8.83 & 0.24 & 0.89 \\
\hline
\end{tabular}

$A$ : 嘎查面积 Area of Gacha $P N$ : 斑块数目 Patches number $P D$ : 斑块密度 Patches density $D_{i}$ : 距离指数 Distance index $A_{i}$ : 斑块面积 Patches size $A A_{\mathrm{i}}$ : 平均斑块面积 Average patch size $E D$ : 边界密度 Edge density $S_{i}$ : 面积指数 Size index $N_{i}$ : 分离度 Isolation index

$\mathrm{T}_{1}$ : 贺日斯台嘎查 Herisitai Gacha $\mathrm{T}_{2}$ : 舒日根台林场 Surigentai forestry center $\mathrm{T}_{3}$ : 巴音胡舒嘎查 Bayinhushu Gacha $\mathrm{T}_{4}$ : 舒日根台嘎查 Surigentai Gacha $\mathrm{T}_{5}$ : 查干敖包嘎查 Chaganaobao Gacha $\mathrm{T}_{6}$ : 图古日格嘎查 Tugurige Gacha $\mathrm{T}_{7}$ : 查干淖尔嘎查 Chagannaoer Gacha $\mathrm{T}_{8}$ : 巴斯海嘎查 Basihai Gacha $\mathrm{T}_{9}$ : 道图淖尔嘎查 Daotunaoer Gacha $\mathrm{T}_{10}$ : 巴彦塔拉嘎查 Bayantala Gacha $\mathrm{T}_{11}$ : 巴彦门德嘎查 Bayanmende Gacha $\mathrm{T}_{12}$ : 蒙古勒金嘎查 Menggulejin Gacha $\mathrm{T}_{13}$ : 宝尔胡吉尔嘎查 Baoerhujier Gacha $\mathrm{T}_{14}$ : 巴彦查干嘎查 Bayanchagan Gacha $\mathrm{T}_{15}$ : 柴达和嘎查 Chaidahe Gacha $\mathrm{T}_{16}$ : 塔安图嘎查 Taantu Gacha $\mathrm{T}_{17}$ : 巴彦都胡木嘎查 Bayanduhumu Gacha $\mathrm{T}_{18}$ : 那日斯图嘎查 Narisitu Gacha $\mathrm{T}_{19}$ : 吉尔嘎郎图嘎查 Jiergalangtu Gacha $\mathrm{T}_{20}$ : 塞音胡都 嘎嘎查 Saiyinhuduga Gacha

\section{2 疏林斑块面积特征}

比较各个嘎查所含斑块面积,贺日斯台苏木舒日 根台林场、塞音胡都嘎苏木吉尔嘎郎图嘎查、乌日图 苏木蒙古勒金嘎查和那日图苏木道图淖尔嘎查所含 斑块面积较大, 都在 $30 \mathrm{~km}^{2}$ 以上, 是主要分布区。比 较斑块平均面积, 以贺日斯台苏木舒日根台林场、查 干敖包嘎查和图古日格嘎查的平均斑块面积较大 $\left(>2 \mathrm{~km}^{2}\right.$ ), 破碎化程度较低。其它嘎查都在 $2 \mathrm{~km}^{2}$ 以 下，大部分介于 $1 \sim 1.5 \mathrm{~km}^{2}$ 之间,破碎化程度较高。

\section{3 边界密度}

边界密度是斑块单位面积所拥有周长的度量。 该值越大, 说明边界皱褶程度大, 斑块被边界割裂程 度高。比较各个嘎查之间边界密度, 发现差异较大 (2.50 11.00 km-1), 介于中间值的较少。说明这 些斑块边界割裂严重, 更容易受外界影响, 所以需要 及时加以保护。

\section{4 斑块密度}

斑块密度直接表明了单位面积区域内斑块的破 
碎化程度。本研究区域主要疏林斑块分布嘎查之间 的密度都介于 $0.10 \sim 0.29 \mathrm{~km}^{-2}$ 之间, 斑块密度不 高。

\section{5 斑块分离度}

分离度用来分析景观要素的空间分布特征, 分 离度越大, 表示斑块越离散, 斑块之间距离越大。比 较主要分布区内玟块的分离度, 多数嘎查在 $0.8 \mathrm{~km}$ 左右。说明各个嘎查内斑块分离程度相似。

\section{6 群落相似度}

为了确定榆树疏林核心区的边界, 需要对保护 疏林群落的相似性加以分析。群落相似性表示随着 距离核心群落的增加, 观察样方群落的物种组成与 核心群落的相似程度。根据调查结果 (表 2), 发现 随着距离增加, 群落相似度下降, 距离增加的越多, 群落相似度则加速下降, 而且采样点之间群落相似 度差异增加。如果以相似度大于 $50 \%$ 为标准, 有效 的保护距离为 $300 \mathrm{~m}$, 距离增加则群落相似度降低; 如果距离超过 $1000 \mathrm{~m}$, 与核心区群落的相似性降低 到 $10 \%$ 以下, 群落的保护价值大大降低。因此, 从 疏林斑块向外延伸 $1 \mathrm{~km}$ 能够有效包含疏林斑块的 群落特征。

表 2 随着距离增加样方群落相似度的变化

Table 2 The changes of community similar in samples along the different distances from the typical patch in Hunshandak Sandland

\begin{tabular}{ccc}
\hline $\begin{array}{c}\text { 距离 } \\
\text { Distance }(\mathrm{m})\end{array}$ & $\begin{array}{c}\text { 固定沙丘 } \\
\text { Fixed sandy dune }\end{array}$ & $\begin{array}{c}\text { 低地草原 } \\
\text { Low grassland }\end{array}$ \\
\hline 100 & $66.7 \pm 1.4$ & $71.2 \pm 0.7$ \\
300 & $57.2 \pm 3.3$ & $65.3 \pm 2.6$ \\
500 & $40.4 \pm 7.9$ & $56.7 \pm 5.4$ \\
800 & $11.8 \pm 10.4$ & $32.8 \pm 8.2$ \\
1000 & $4.7 \pm 13.6$ & $7.5 \pm 10.7$ \\
\hline
\end{tabular}

\section{3 结 语}

由于计划将整个正蓝旗建设成为一个自然保护 区, 所以本研究以正蓝旗为拟建保护区整体进行分 析。本研究区域中 20 个嘎查所含疏林斑块面积较 多,占该旗疏林斑块总面积的 $86 \%$, 是主要分布区。 通过对主要疏林斑块分布区的分析, 发现疏林斑块 密度较低, 斑块边界割裂严重, 斑块之间分离度高, 大斑块较少, 小斑块数量多, 破碎化严重, 需要及时 加以保护。其中, 贺日斯台苏木、塞音胡都嘎苏木、 那日图苏木和乌日图苏木各主要疏林斑块分布区之 间能连成一片，而桑根达来镇和塞音胡都嘎苏木的
部分嘎查距离较远 ( > $10 \mathrm{~km}$ ), 且中间被道路、城镇 隔离。同时, 扎格斯台淖尔苏木有几个嘎查也含有 疏林斑块, 但是其所含面积较小 (占总斑块面积的 $14 \%)$, 而且斑块之间分离度较大 (3.26 km), 并且与 主要分布区域——贺日斯台苏木-那日图苏木-乌日 图苏木-塞音胡都嘎苏木之间距离较远 $(>30 \mathrm{~km}$ ), 所以没有作为核心区加以分析。根据选取相近原 则,可以选取贺日斯台苏木的巴音胡舒、舒日根图、 舒日根图林场、贺日斯台、图古日格、查干敖包嘎查, 那日图苏木的巴斯海、道图淖尔、巴彦塔拉、查干淖 尔、巴彦门德嘎查, 乌日图苏木的蒙古勒金、巴彦查 干、宝尔胡吉尔嘎查, 塞音胡都嘎苏木的全部嘎查, 桑根达来镇的额尔敦达来、柴达和嘎查作为潜在核 心区。由于潜在核心区各个疏林斑块之间互不相 联, 与整体保护原则不相符合, 造成人为隔离, 也不 利于核心区的巡护保护, 因此需要将这些破碎化的 疏林斑块联合起来。运用 ArcGIS 的缓冲区分析功 能, 分别设置不同宽度的缓冲带, 发现设置 $3 \mathrm{~km}$ 以 内的缓冲距离能够将潜在核心区内的疏林斑块联合 起来, 所连接的斑块数量最多, 而占用非疏林斑块土 地面积最少 (图 1)。而且, 根据群落相似度调查, 以 及榆树种子传播距离 (集中散布在 $500 \mathrm{~m}$ 以内)(张 敦论等, 1984), 此距离也保证了潜在土地的保护。

观察潜在核心区分布, 可以发现在利用 ArcGIS 缓冲区设计的核心区之间仍然存在着空隙, 也就是 没有被划定为保护核心的空白区域。如果不做进一 步调整, 就会使核心区边界过于皱褶, 不仅浪费土 地, 增加建设成本, 而且也不利于疏林的整体保护。 因此,在完全封闭的空白区域，应当划定为核心区; 在半包围地段, 则按照两端疏林斑块的边界取平滑 线边界, 将靠近疏林斑块的地段划进核心区(图 1)。 由此而划定的核心区,共包括疏林斑块面积、缓冲带 面积和空白区面积共计 $1531 \mathrm{~km}^{2}$, 分布在 23 个嘎 查, 占全旗总面积的 $13 \%$ 。

本研究主要按照岛屿生物地理学设计原则进行 设计, 保护区核心区: 1) 尽量扩大面积;2)尽量设计 成圆形; 3 )如果有多个核心区, 应当设置生态走廊带 将其相连;4)多个核心区应当尽量靠近。虽然岛屿 生物地理学设计保护区的原则存在一些争论, 但它 仍然是目前应用较多的自然保护区设计原则 (Noss \& Cooperrider, 1994; 李义明和李典谟, 1996; 邬建 国,1990), 而且也适合以疏林斑块为对象的取舍决 策。因为这些设计原则也与景观生态学中的景观斑 


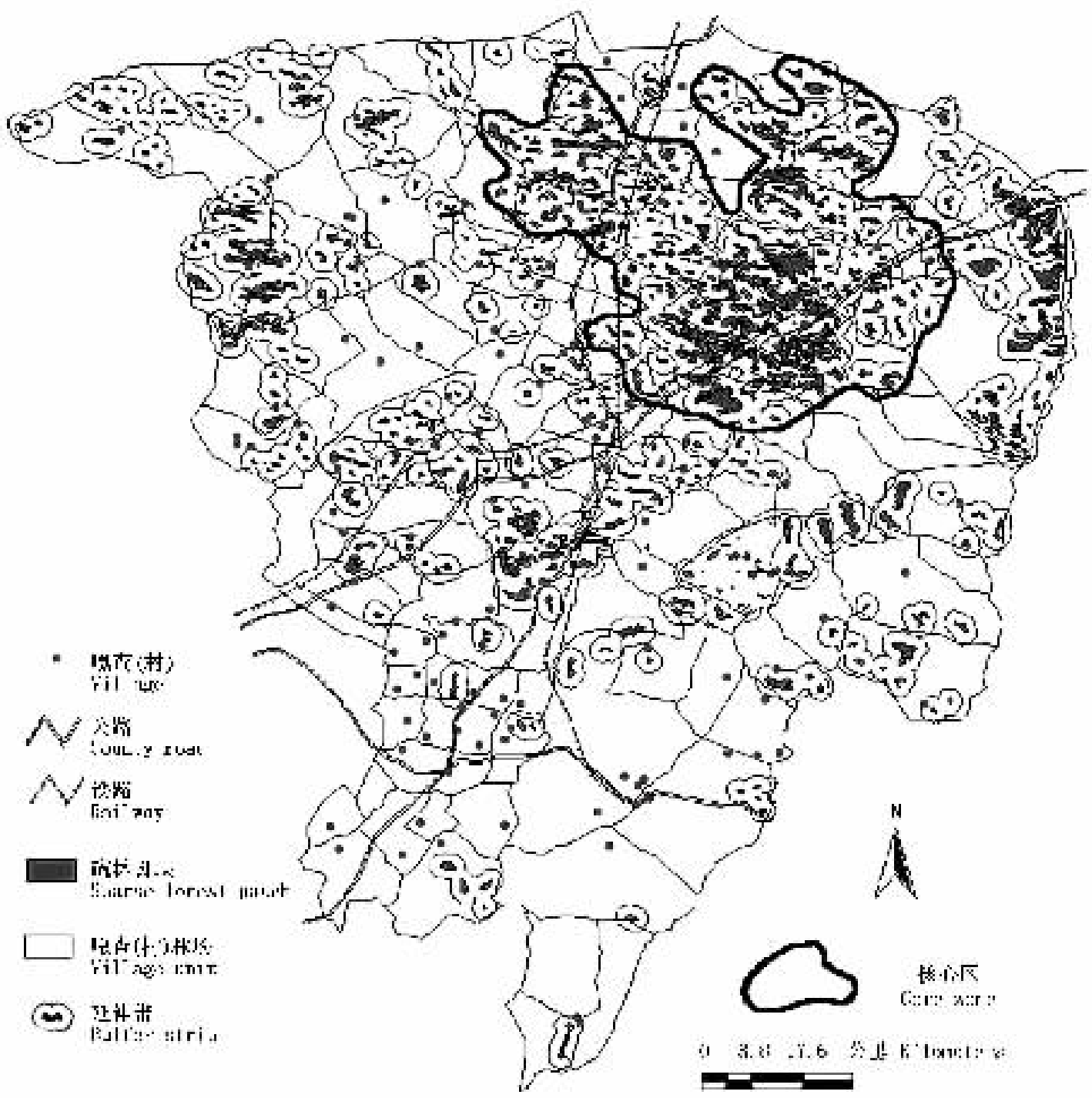

图 1 浑善达克沙地正蓝旗境内榆树疏林斑块分布、斑块延伸带以及潜在核心区位置图

Fig. 1 The map of Ulmus pumila sparse forest patches location, core zone design for the potential nature reserve in Zhenglan Banner, Hunshandak Sandland

块原理相似。景观破碎化是生物多样性丧失的重要 原因之一(马克明和傅伯杰, 2000; 肖笃宁, 1991), 景 观破碎化主要表现为斑块数量增加而面积缩小, 斑 块形状趋于不规则, 内部生境面积缩小, 廊道被截断 以及斑块彼此隔离( 陈利顶等, 2000)。景观破碎化 会对生存于其中的物种带来一系列的影响, 如影响 种群的大小和灭绝速率、扩散和迁入、种群遗传和变 异、种群存活力等; 改变生态系统中的一系列重要关 系, 捕食者-食物、寄生物-寄主、传粉者-植物以及共 生关系等(邬建国, 2000; 肖笃宁, 1991)。在进行保 护区核心区的决策时, 首先考虑的应当是疏林斑块 的面积、破碎化程度等指标。

本研究中, 潜在核心区内还含有城镇、厂矿、道
路,或者人口居住点。因此需要对核心区的边界作 进一步修订。这些修订需要将保护区的缓冲区设计 结合起来, 做进一步研究。最后核心区的具体边界 确定还需要当地政府、居民和社区各方面协商解决 确定。

\section{参 考 文 献}

Chen LD (陈利顶)，Fu BJ (傅伯杰)，Liu XH（刘雪华） (2000). The landscape design and species conservation for nature reserve, taking Wolong Nature Reserve as a case. Journal of Natural Resources (自然资源学报)，15,164-169.(in Chinese with English abstract)

Cui GF (崔国发), Li JQ (李俊清), Niu SK (牛树奎)（2000）.

The establishment and design of Beijing Labagoumen Nature Reserve. Journal of Beijing Forestry University (Natural Science 
Edition) (北京林业大学学报 (自然科学版)), 22, 40-46. (in Chinese with English abstract)

Huslshoff RM (1995). Landscape indices describing a Dutch landscape. Landscape Ecology, 10, 101 - 111.

Kingsland S (2002) . Designing nature reserves: adapting ecology to real-world problems. Endeavour, 26, 9-15.

Li WH (李文华), Guo JP (郭江平), Zhao Q (赵强) (2000). Background evaluation and plan for natural desert reserve construction in Ebinur Lake, Xinjiang. Journal of Desert Research (中国沙漠), 20,278 - 283. (in Chinese with English abstract)

Li YM (李义明), Li DM (李典谟) (1996). The principle theories and methods for nature reserve design. Chinese Biodiversity (生物多样性) , 4, 32-40. (in Chinese with English abstract) Ma KM (马克明), Fu BJ (傅伯杰) (2000). Landscape pattern and fragmentation in Donglingshan Mountain region. Acta Phytoecologica Sinica (植物生态学报), 24, 320-326. (in Chinese with English abstract)

Ma KP (马克平) (2001). Hotspots assessment and conservation priorities identification of biodiversity in China should be emphasized. Acta Phytoecologica Sinica (植物生态学报), 25, 124 125. (in Chinese)

Noss RF, Cooperrider AY (1994). Saving Nature's Legacy: Protecting and Restoring Biodiversity. Island Press, New York, 131 -132 .
Pielou EC (1994). The Interpretation of Ecological Data: a Primer of Classification and Ordination. John Wiley \& Son, New York, $264-269$.

Riitters KH, O' Neill RV, Hunsaker CT (1995). A factor analysis of landscape pattern and structure metrics. Landscape Ecology, $10,23-29$.

Schumaker NH (1996). Using landscape indices to predict habitat connectivity. Ecology, 77, $1210-1225$.

Tang XP (唐小平) (2003). Basic ecological traits of the ThreeRivers' Sources area and the design of the nature reserve. Forest Resource Management (林业资源管理)，(1)，38 - 45. (in Chinese with English abstract)

Wu JG (邬建国) (1990). The theory of nature reserve and the theory of MacArthur-Wilson. Acta Ecologica Sinica (生态学 报), 10, 187 - 191. (in Chinese with English abstract)

Wu JG (乌建国) (2000). Landscape Ecology: Pattern, Process, Size and Scale (景观生态学一一格局、过程、尺度与等级). Higher Education Press, Beijing, 155 - 198. (in Chinese)

Xiao DL (肖笃宁) (1991). Landscape: Theory, Method and Application (景观生态学理论、方法与应用). China Forestry Publishing House, Beijing, 258 - 301. (in Chinese)

Zhang DL (张敦论), Lin XF (林新福), Wang TZ (王铁章) (1984). Ulmus pumila (白榆). China Forestry Publishing House, Beijing, 16-64. (in Chinese) 